\title{
Minding Machines: A Note on Alienation
}

\author{
Sascha Engel
}

This paper ${ }^{1}$ discusses an underrepresented dimension of contemporary alienation: that of the machines, both smart and dumb, which share the everyday lives of contemporary humans. From household items connected in the 'Internet of Things' to ubiquitous smartphones, I focus on 'smart' machines to suggest that a form of alienation manifests in their functionalist use and description; that is, in descriptions of such machines as mere tools or testaments to human ingenuity. These descriptions underestimate the real and often capricious existence of machines as everyday material entities. In a world overdetermined by smart machines, it is high time to abandon their characterization as basic tools and to re-embed former Homo Faber into her Google Home.

To restore this machinic dimension, I first suggest an analytics of alienating machines - machines contributing to human alienation - and then an analytics of alienated machines - machinic alienation in its own right. The focus in these discussions is on smart machinery, from smartphones to commercial platform APIs, as these are ubiquitous in today's technosphere. This is not to say that the present argument is not applicable to dumb machines, from harvesters to vacuum cleaners. Yet in smart machines, the problem poses itself more forcefully. On the one hand, the developed countries are now nearly saturated with them, and they have become indispensable everyday companions - without, however, being recognized as such. On the other hand, the rapidly developing extrapolation of smart machinery into autonomous or intelligent machinery renders a conversation about machinic alienation an urgent necessity. Based on this conversation, I derive some approaches for addressing machinic alienation, and I conclude with some thoughts on the benefits of doing so in the context of developing Artificial Intelligence.

\section{The Concept of Alienation}

Despite its widespread use and abuse - to the point where it "has proved a highly profitable commodity in the cultural marketplace" (Jay 1973: xiii) - the term 'alienation' continues to denote a discernible phenomenon in contemporary capitalism. Its pervasive presence in contemporary relations of production has been predicted in its classical account as described by Karl Marx at the inception of the industrial revolution. In this account, alienation is constitutive of the capitalist mode of production in its entirety. Because labor is alienated under capitalism, it produces "for the rich wonderful things - but for the worker it produces privation. It produces palaces - but for the worker, hovels. It produces beauty - but for the worker, deformity" (Marx 1844/1975: 73). Alienation is here, first, alienation of the worker from her or his own product. Due to this separation, the worker is forced to purchase for survival the very products which his or her labor produced in the first place (ibid: 72).

Alienation further denotes a separation between workers and the means of production by which these workers produce palaces and hovels for capitalist and laborer, respectively. On the one hand, this side of alienated labor is the alienation of workers from nature, which is appropriated and plundered for the enrichment of those owning the means of production (Marx 1844/1975: 75-76). On the other hand, alienated workers confront their own labor, as well as nature, crystallized in the means of production owned by someone else and used to exploit them. Machinery, in particular, confronts workers as the "consolidation of what we ourselves produce into an objective power above us, growing out of our control, thwarting our expectations, bringing to naught our calculations" (Marx and Engels 1845/1975: 160). 
Industrial machinery is thus an alienating force, employed by the capitalist class at the expense of the laboring class. Indeed, the historical ascent of the bourgeoisie is that of industrial machinery and, along with it, alienated labor. The bourgeoisie "puts the interests of technique before the interests of individuals, who had to be sacrificed in order that technique might progress" (Ellul 1964: 53). Under capitalism, the machine serves as an instrument of ever-increased alienation. Removing the workers from the means of production and the products of their labor, capitalist production eventually "replaces labor by machines - but some of the workers it throws back to a barbarous type of labor, and the other workers it turns into machines" (Marx 1844/1975: 73).

This does not mean, however, that machinic imperatives are somehow in a position of dominance in the power relations characterizing the alienation at work in capitalist labor. Capitalist technocracy remains capitalist first and foremost (Meynaud 1968: 30-31). Far from liberating machinery, capitalist production confines it to subordinate status within the bourgeois socio-economic architecture: "It is solely because the bourgeoisie made money, thanks to technique, that technique became one of their objects" (Ellul 1964: 53). Machines, like humans, serve as a means to exploit nature for profit. For Marx, industrial machinery represents dead labor confronting living labor, human exertion crystallized in automata coercing new human exertion (Marx 1844/1975: 78). Machinery is thus a crystallized form of human alienation: an alienated product accumulating by alienating the labor which creates it.

Machinery has developed a long way since Marx. Through the second industrial revolution of the mid-20th century, introducing cybernetic and homeostatic feedback machinery, and the digital revolution of the late 20th century, machines have come to be miniaturized and ubiquitous in everyday lives (Ihde 2015). At the same time, they have become 'smart': rather than simply maintaining equilibria, as homeostatic machines did in the mid-20th century, 'smart' machines are capable of algorithmic self-improvement, getting better at their tasks or adjusting to new tasks autonomously. Nevertheless, the classical understanding of machines as forces assisting in the alienation of humanity and nature remains widespread among critics of capitalism. Social critic David Noble (1993: 12), for example, traces the history of political economy as a history of an "apologetics for unrestrained technological progress," which ignores the human alienation manifested in machinery. For Noble, machinery crystallizes Marx's two aspects of alienated labor. First, industrial machines alienate the products of labor by allowing ever-more distant machinic apparatuses to take control over human labor connected with it. Secondly, industrial machines alienate the process of labor itself, allowing 'entrepreneurs' to conceive of the factory as a "vast automaton" and of "capitalist industry as the very embodiment of reason, against which worker opposition could not but appear to be futile and irrational" (ibid).

At the present point of machinic history, this focus on machines as tools alienating humans is no longer fully adequate. On the one hand, are the smart, connected machines sharing everyday households today not themselves members of those households, at least in some sense? On the other hand, as the boundaries blur between labor and machine in APIs underlying zero-hour work, does code itself labor in some sense? Finally, how would one extrapolate such questions to the complex of Artificial Intelligence? Must smart machines impose "visions human obsolescence" in an environment "of our own making" which nevertheless "assumes we must timidly become the victims of the culture we have created" (Roszak 1994: 43)?

\section{Analytics of Alienating Machines}

Tracing the history of the integration of capitalist labor into industrial and post-industrial machinery shows no sign of decreasing alienation. Beyond the industrial factory, an analytics of machinic alienation finds the familiar two aspects of Marx's concept of alienation at work throughout the capitalist economy: alienation of the worker from the product by means of machinery, and alienation of the worker from the process of labor, likewise by means of machinery. Neither of these aspects has changed since the inception of the so-called service economy, and indeed both are going strong despite pronouncements of 'creative classes' and 'knowledge workers' for whom machinery is said to liberate creativity (Florida 2014).

Alienation by machines remains at the core of capitalist production in the 20th and 21 st centuries. The continuities are strong. In contemporary FIRE sector offices as on the Fordist factory floor, once "the traditional work of the craftsman is subdivided into its constituent tasks and performed in series by a chain of detail workers,... the instrument of labor is removed from the worker's hand and placed in the grip of a mechanism" (Braverman 1974: 169). This mechanism alienates the workers' product and confronts them in the process of production as an 
alien force. On the early 20th-century factory floor, the Fordist "assembly-line system is alienating primarily because the worker becomes a virtual cog in the machine, performing a narrow, piecemeal productive function" (Agger 1992: 189). In the paper offices of the 1970 s, keypunching machinery played a similar role, keeping large amounts of workers in low-paid, no-challenge, menial jobs, alienating them from the processes of production and their products (Braverman 1974: 331-337). In the (ostensibly) paperless offices of today's call centers, the filling of spreadsheets works in a similar way, bathing hunched-over workers in the light of rows of alienating screens - not to mention the everyday degradation felt by those whose headsets are plugged into call center operating systems.

In all three cases, "human instruments are adapted to the machinery of production according to specifications that resemble nothing so much as machine-capacity specifications" (Braverman 1974: 180). In customer service, regulated bathroom breaks, per-hour targets and service level agreements transform workers into plugged-in machines. In food delivery apps, this takes the form of by-the-second accounting of labor time, along with time and routing requirements (Jones 2018). This latter mode of alienation by machines is increasingly dominant and ubiquitous:

If you are taking a closer look at templates of 21 st-century work that are currently put in place, you will notice a trajectory of workers taking on many gigs at once [in] subcontracting and rental economies with big payouts going to small groups of people. Occupations that cannot be off-shored, the pet walkers or home cleaners, are now subsumed under platform capitalism. [...] Companies like Uber and airbnb are enjoying their Andy Warhol moment, their $\$ 15$ billion of fame, in the absence of any physical infrastructure of their own. They didn't build that - they are running on your car, apartment, labor, and importantly, time. They are logistics companies where all participants pay up the middleman: the financialization of the everyday 3.0. (Scholz 2015)

For over a third of the U.S. workforce, tethered to platform APIs, their smartphones act as alienating forces (McCue 2018). The remaining two thirds, too, are embedded into machinic alienation. Across the economy, one might thus classify two modes of machine-based alienation.

1. For the two-thirds of workers in the spreadsheet economy, computing machines do not just produce cheaply and quickly - from the predictive algorithm providing pre-filled email communication to automated spreadsheets and modular programming suites. Like their counterparts in the Fordist factory, computing machines also serve to break possible labor resistance. In the industrial economy just as the spreadsheet economy, the more work processes are sourced on computing machines, the more management surveillance becomes possible, from 'quality control' to time measurement (Braverman 1974: 170). In present-day spreadsheet jobs, direct control of a worker's internet and intranet behavior allows conclusions not only about the worker's productivity but also their personality (Booth 2019). What is more: in the 1970s, machines alienated workers in the form of boring drudgery or monotonous, repetitive tasks (Braverman 1974: 195). This has certainly not vanished today. Indeed, boredom at work is so pervasive now that it is being reinterpreted as a virtue: "boredom is a warning signal that we've become stagnant, we may have lost sight of our goals, and it's time to create change" (Sturt and Nordstrom 2018).

2. In the gig economy tethered to platform APIs, direct integration of humans into the machinic circuitry of continuous API calls is the most widespread way in which computing machines alienate labor. Managerial control of worker output and the manner in which it is achieved has in no way lessened since the industrial economy. Quite the contrary: in the 'gig economy', the subjection of workers to mechanically mediated managerial control has reached new heights, as real-time workplace surveillance comes to be replaced by the self-management of the workers through the platforms to which they sell their services. As full-time employment gives way to the precarity of formally self-employed app-based work, managerial control takes on the new form of metrics-based measurements in whose continuous review the livelihoods of reviewees are all the more at stake as they are reviewer and reviewee at the same time. Low-level managerial and technical staff, too, are integrated to assure API calls are done accurately, providing the behind-the-scenes spreadsheet and programming work enabling workers to perform tasks in a faster and ostensibly qualitatively better fashion. Before the contemporary economy of viral reviewing developed, this was mostly a question of motivating workers to work more (Heskett 1987). Now, a continuous review is mostly a question of maintaining precarity to ensure apps 'users' work better and work more (Coyle 2018).

It comes as little surprise, then, that emancipatory perspectives tend to describe machinery as a force actively complicit in alienation and exploitation. Thus, for example, Herbert Marcuse advocates "the end of alienated labor," which he argues will be "based on the rational mastery of existing technology" (Agger 1992: 94). Such mastery manifests, for Marcuse, as "workers' control of the technological apparatus," such that "workers are able to understand and manipulate the productive apparatus so that it does not dominate and discipline them" (ibid: 189). From this perspective, it may well seem that a change of machinic ownership - perhaps towards worker-operated forms of production in the spreadsheet economy, and calling into question the existence of zero-hour contracts and call centers - would emancipate workers. After all, "past or dead labor takes the form of capital" because the "means 
of production [are] the property of the capitalist" (Braverman 1974: 227).

\section{Analytics of Alienated Machines}

Yet this overlooks an entire dimension of alienation. To be sure, machinery does serve to alienate the workers of today, as it did in the 20th and 19th centuries. To a significant extent, however, alienation of humans by machines is part of a more general structure in which machines themselves are alienated. This is not simply due to the legal relations of ownership of machinery. Machinery is not a simple instrument for the alienation of workers by capital, to be replaced by worker control in an emancipatory movement. Nor is machinery inherently alienating, as some primitivists have it (Zerzan 2012). The question at hand goes much further. As Gilbert Simondon argues,

the most powerful cause of alienation in the contemporary world resides in this misunderstanding of the machine, which is not an alienation caused by the machine, but by the non-knowledge of its nature and its essence, by way of its absence from the world of significations, and its omission from the table of values and concepts that make up culture (2017: 16).

Such banishment of machines from thought is near-universal. It manifests primarily in two different ways (Simondon 2017: 17). The first sees machines as mere tools or gadgets, thereby neglecting reflections on their presence altogether. This form of neglect goes back to Marx's own time. When historian Siegfried Giedion wrote his history of machines, tools, and furniture in the 1940s, he found that

an amazing historical blindness has prevented the preservation of important historical documents, of models, manufacturer's records, catalogues, advertising leaflets, and so on. Public opinion in general judges inventions and production exclusively from the point of view to their commercial success... This means the discarding of time, both past and future (1948: v).

The same happens with the productive machinery sharing everyday work lives in industrialized countries today. Widespread ignorance of the designs, structures, and inner details of everyday machinic companions is actively encouraged at a time when attempts to repair computing machines are effectively rendered legal offenses. ${ }^{2}$ To be sure, this does not mean that the forgetfulness of machines is total. One could well argue that computer literacy is at an all-time high. Such literacy is at an application level, however. One will know how to perform the troubleshooting steps prescribed by applications - clearing caches and cookies, and so forth. In this sense, awareness of machinic presence does certainly exist. Yet, who knows whether all cookies have really been cleared - or how many other stacks store one's data which the application does not reach.

What is more, reflections on the effects of app-based living are made substantially more difficult due to the neglect of more in-depth exploration of machinic presence. Smartphone presence is certainly widely recognized as ubiquitous. Yet its precise mode remains underexplored. Instagram does not merely slow down food consumption in fancy restaurants - it also redefines the boundaries of sociality. This has been explored with an eye to the alienation and exploitation of social media 'users' (e.g. Fisher 2012). Likewise, social media influencing has been explored for its pernicious effects on body images, modeled ever more towards continuous beauty-industrial consumption (Cheney 2010). What remains underexplored in these perspectives, however, is the mode of machinic activity underlying it. Social media influencing is based on forms of the algorithmic weighting of factors human and non-human, such as clicks and likes, on the one hand, IP signal distribution and crawler hits on the other. The latter two, in turn, stem from automated non-human processes: the distribution of packet-switched signals, and the response of search engine algorithms to the Internet's 'long tail' distribution, respectively. These do matter - not least, for privacy, piracy, and 'hacking' concerns - but remain invisible to the vast majority of users whose expertise ends at clearing their caches and cookies.

Other examples abound. Planned obsolescence requires ignorance of production and waste disposal processes, while the maintenance of copyright law - and the persistence of flimsy advertising - require ignorance of real technological developments, or the absence thereof. Transposed to the office and factory floors, managerial control is facilitated by workers' ignorance regarding the systems that monitor them. In the same vein, surveillance is exercised at home by Alexas, Nests, and Google Homes. I will expand on these below.

In addition to alienating because it is unknown, machinery also alienates by overwhelming. Thus the second approach to machines today is a sort of shock-and-awe submission. Here, too, the machine is present but its inner workings remain obfuscated - this time more deliberately so. This is most obviously represented by the effects of 
military-industrial machinery, with warships and flyovers awing civilian audiences, or in the form of intentionally unknowable bot swarms. In civilian life, shock and awe are replicated by advertising industries ensuring that the glamour of supposed technological advance falls onto the latest gadget, regardless of its actual performance or improvements. Like the historical blindness described by Giedion, this feeling of awe comes with ample historical precedent. Historian Henry Adams has described it in 1918, saying he "began to feel the forty-foot dynamos as a moral force" when visiting a factory floor,

much as the early Christians felt the Cross. The planet itself seemed less impressive, in its old-fashioned, deliberate, annual or daily revolution, than this huge wheel, revolving within an arm's length at some vertiginous speed, and barely murmuring - scarcely humming an audible warning to stand a hair's-breadth further for respect of power... Before the end, one began to pray to it (Adams 1918/1999: 37).

As in the first approach, the machine itself remains unknown, and deliberately so, as its overpowering effect can only be achieved when its workings and shortcomings remain hidden. The shortcomings of military hardware are the best example of why such willful obfuscation is a strategic necessity. A 2016 report by the Center for Strategic and International Studies found that the U.S. armed forces have spent more than USD 50 billion on abandoned projects in the previous decade, ranging from canceled tank modernization programs and abandoned air and space endeavors to vanity projects such as new presidential helicopters (Harrison 2016: 10). Bot swarms, too, rely more on the diffuse feeling of 'democracy under threat' than actual efficacy: supposedly Russian 'hacking' of Western elections caused shockwaves in 2016, but has had few empirically observable effects (Berghel 2017). Even those machines not abandoned at various stages of their project lives are not nearly as terrifying as militaries and intelligence communities need civilians to believe.

In both cases, the machine is relegated to a "structureless world of things that have no signification but only a use, a utility function" (Simondon 2017: 16). The machine alienates because it is itself alienated. Anonymously exploited to serve the ends of its owners, its very structure points to its status as a subordinate facilitator of capitalist accumulation. Neutralized and obfuscated, the app dictating, for example, the delivery cyclist's routes and times is, after all, merely a transducer accepting any syntactically well-structured input, and transposing its elements to generate equally well-structured output (Denning, Dennis, and Qualitz 1978: 4-5).

Yet the cyclist's smartphone has a presence beyond transduction, as indeed does the API governing the payment flows setting the cyclist in motion. Just as, for Marx, human workers are alienated from their "essential being," their "spontaneous activity" (Marx 1844/1975: 74), so the alienated machine has an underlying spontaneous activity from which it is alienated. Constituting it as a mere tool or gadget, or an awe-inspiring monstrosity ignores the machine's own capricious presence. Alexas and Google Home may not have the same subjective agency that the cyclist has, and from which the cyclist is alienated. They do, however, possess actancy: situational presence which is not fully nonhuman but decisively not fully human. That is, they labor in the vibrant network of a household, co-constituting it as a space in which "each of the actants possesses a unique signature" (Latour 1993: 86). The effects of the presence of an Alexa range from the mundane to the troubling. Thus, the well-known problem that Alexas occasionally respond without being called to do so easily leads to troubling conclusions about privacy. Whether by law enforcement or by less state-driven efforts, Alexas generate spaces in which every sound is potentially used against Alexa's co-inhabitant. This manifests machinic actancy, as it changes the spaces affected and alters human behavior (Chung et al 2017). Yet more actancy is discernible with regards to the psychological effects of an Alexa. Thus, cognitive science is exploring the effects of Alexa's kin on children's development; from politeness to virtual assistants to the latter's effects on children's way of processing information (Gonzalez 2018).

In none of these cases, Alexa is a mere inert tool. The eerie actancy of Alexa responding without being activated is not exclusively due to Alexa's household co-inhabitant, nor its producer. It is an effect of programmatic structures whose materiality is pressed into the service of its corporate owner. Likewise, Google Home's surveillance actancy, while embedded in a web of statist security discourse, surveillance capitalism, and uncontrollable bureaucratic proliferation, is nevertheless distinct from these. Even the cyclist's zero-hour app, ostensibly more directly embedded into the economic and legal structures of platform capitalism than Alexa, holds actancy of its own: integrating an API, it implements the latter's stratagems contained in its API call structure, and whose quirks often counteract its commercial purpose. A common example for the latter are the requirements of programming languages as they clash with commercial or legal requirements. Thus, for instance, the conversion of non-Latin alphabets frequently causes issues for platform APIs verifying their users. 


\section{Errors, Glitches, Generative Networks}

Alienation of machines goes yet further than actancy, however. A smart machine's essence is not exhausted in its effects on its environment. Its essence can rather be conceptualized more broadly as its technicity: the way in which it implements an abstract object - such as a smartphone type - in a concrete situation, uniting the characteristics of the abstract object, the aberrations from it which make it this concrete object (and thus more than an instance of the abstract object), and the characteristics of that situation (Simondon 2017: 72). The machine's technicity gives it an actancy in a given situation, where it registers as a presence. Such presence can manifest in dumb machines as material efficacy, as when a machine illuminates or warms, or conveys or transports. In smart machines, it plays out as a series of symbols by which the machine, while "incapable of will and bias," is nevertheless "capable of showing, signing, writing, and scribbling” (Latour 1993: 23). Accounting for this allows taking stock of the machine's vibrant solidity, its warmth, its sounds and noises, its raw constructive and destructive energy (Smith 1998). The appropriation and overdetermination of a machine's technicity and actancy alienates it.

A seemingly fairly mundane example for this are so-called errors. On their surface, errors are malfunctions interrupting the normal way an app or, more generally, a computing machine should behave, and forcing human users to invest time and resources into fixing the recalcitrant machine. Yet, this view, once again only reflects alienated machines confined to the "structureless world of things that have no signification but only a use, a utility function" (Simondon 2017: 16). Unpacking this imposition makes it clear that not all interruptions of machinic activity are errors. On the one hand, there are blips and crackles which remain below a threshold, making them an error. Thus, packet-switched messaging in server-to-server communication entails redundancies rendering individual issues in individual packets ineffective. Likewise, multiplexed busses between computer hardware elements always come with safeguards against individual blips during transmissions (Mamidipaka, Hirschberg and Dutt 2004). On the other hand, there are functionally necessary interruptions, such as loading, buffering, and synchronization times for apps, or downtimes for servers. These likewise do not constitute an error. What defines them as errors is an error handler setting a certain threshold beyond which aberrations manifest as such.

Beneath error handling lies a range of blips and glitches. The blip is, in itself, nothing but a sequenced pattern received in lieu of another sequenced pattern. Indeed, as pure sequence received it is not, initially, an aberration at all. Rather, it is merely a part of the sequence at hand. If a sequence 0110 is received, the 0110 must first be constituted as an aberration from, say, an expected sequence 0101. Thus a classical account of error handling, "instead of a pair of like digits, 00 or 11, we have received a pair of unlike digits, 01 . We don't know whether the correct, transmitted pair was 00 or 11. We have detected the error, but we have not corrected it" (Pierce 1961: 149-150). Only when the aberration is contrasted with an assumed 'original' - that is, when the 0110 received is overwritten by a 0101 - does the former become an error. The result are error libraries, taxonomies of machinic malfunction - and thus of their correct function.

Such error handling alienates the rich technicity of computing machines of all types. As artists such as Ryoji Ikeda demonstrate, glitches make vast source material for art. While still arranged by human composers, such glitch art nevertheless manifests the machine's own materiality in a way that allows its actancy to manifest itself. Nor is this metaphorical: besides offering "ways of disrupting the finality of the music commodity," glitch "exposes the medium as such," bringing the materiality of computed sound directly to the ear (Hegarty 2007: 182, 189). In many ways, too, glitch aesthetics exclude human composition altogether. In the works of Autechre or Merzbow it is difficult to distinguish compositional elements from the effects of labyrinthic arrangements of technology or found sounds, or both. And while these two examples remain within the realm of human attribution (if not human production), fully autonomous art emerges when Generative Autonomous Networks, which are capable of emulating certain more formulaic styles of artistic production, are coupled with algorithms capable of deviating from styles (Elgammal et al. 2017). The result is genuine machinic creativity.

Ranging from error handlers overriding glitches to artists claiming credit for them and their effects pedals' actancy, to corporations owning machinic creativity, machines are alienated from technicity and actancy. Google Deep Dream produces art, but this art is appropriated by copyright law ascribing it to the authors of its algorithm (Stecher 2017). Yet, machinic creativity can also subvert such ownership when it becomes increasingly unclear what art is generated by humans and what by Generative Networks. Glitch-based art, where algorithm and art become indistinguishable, and the creations of Generative Adversarial Networks, where deviations from established styles are at the center of autonomous non-human processes, take this even further. A vast world opens up, ranging from 
the simple recognition of 0110 as a signal of its own rather than a deviation from 0101 , to deepfakes questioning notions of control and communication, property and propriety altogether (Parkin 2019).

\section{Addressing Machines' Alienation}

What if blips and crackles were seen as more than a nuisance to be fixed, or a token of a familiar type to be classified and handled, or as something to be ascribed to supposedly human creativity? Errors may yet come to be seen as reminders of machinic materiality, and glitches and neural network creations as reminders of machinic actancy. What error handling and technical support constitute as a nuisance within alienated production could rather be conceived as an opportunity in a less alienated context. Beneath error handling and technical support, a blip would then be an opportunity to learn something about the computing machine confronting its human companion. It can lay bare the machine's inner structure and mechanisms, and indeed its capricious personality. More than merely a token of a type, the machine at hand can thus come to be seen as an individual existence with which one shares one's life. Instead of discarding one's machinic companion and buying a new one, the error can be seen as an invitation to enjoy understanding things oneself, and understanding them in themselves - thus exploring "computation in the wild: that eruptive body of practices, techniques, networks, machines, and behavior that has so palpably revolutionized late-twentieth-century life" (Smith 1998: 6).

The machinic actancies manifest underneath error handlers and in networked creativity are immediately relevant to political economy. On an individual level, blips may well invite humans to consider their machinic companions in their own right. Yet who can afford to follow this invitation apart from a few hobbyists? From 'entrepreneurs' tethered to platform APIs to socially mediated influencers and influences, alienated human existance requires alienated computing: it has neither time nor resources to live otherwise. It is deliberate that the machinic individuality manifesting in hardware glitches is papered over by software's error handling and diagnostics programs. As a result, and again deliberately, scarcely anyone knows how their computing machine works. This precludes tampering in its various forms and renders 'users' powerless. Thriving do-it-yourself environments would, after all, diminish profits realized by platforms whose profits are entirely based on making connections will capable of coming about without them. What is more, they would also threaten the substantial profits realized by the technical support industry.

What is more, such DIY environments would render obsolete the regimes of planned obsolescence, which take the widespread ignorance of the inner workings of computing machines to its logical conclusion. This, in turn, would affect machine life cycles. Here, too, machinic alienation facilitates capitalist accumulation. Who really knows where their smartphone came from, and where it goes when it is thrown away? Advertising may suggest where Smartphones are ostensibly made, to be sure, but is this information trustworthy? Assembly lines have been distributed globally to networks of alienated machines producing alienated machines for fifty years (Anders 1981: 110-127). The majority of smartphones, for example, claim to be assembled in either China or the U.S., but their parts have traveled much further: Vietnam, Laos, India, South Korea (Schmitt and Schulz 2016). The conditions under which such distributed production works are typical of alienating capitalism: Shenzhen, the Chinese 'silicon valley', which is home to WeChat's Tencent and Huawei among others, is also a site of notorious exploitative brutalization, with "products with razor-thin margins" produced by mostly "migrants from rural areas" working "without many social protections" (Wang 2016).

Likewise, one is led to think that electronics get recycled, perhaps even in an environmentally sound way, by advertising campaigns such as SERI (Sustainable Electronics Recycling International), a Minnesota-based NGO providing certifications for recyclers of electronic waste, or EU directives such 2012/19/EU, attempting to implement sustainable infrastructures for recycling Computers, TV Sets, or smartphones. To be sure, such work does have effects. Nevertheless, a substantial amount of Euro-American electronic trash ends up in African landfills simultaneously used as slums for workers searching scraps for precious metals. The most notorious example is Agbogbloshie in Ghana, where "boys and young men gather in groups, picking their way through piles of old hard drives, untangling wires, and breaking up old air-conditioning units and even irons," to gather and sell scrap metal amid a wasteland "contaminat[ed] with lead, mercury, cadmium, arsenic and flame retardants" (Hirsch 2013).

Alienated machines thus constitute and cause alienation along their life cycle: they confront humans and the environment in production, from mining to assembly; they confront humans and the environment again in usage, from electricity consumed to lives spent online; and they confront humans and the environment when discarded, with 
humans dwelling amid toxins seeping into groundwater. Yet this very ubiquity of machinic alienation - of humans by machines and of machines by humans - opens new vistas of mutual recognition, too (Jaeggi 2014). Geographical dispersal of the sites of machinic production, usage, and waste does not mean that the global apparatus of machinic, human, and environmental alienation is not rooted in the everyday lives of human beings. Here, a starting point for reform arises.

Taking errors seriously as learning opportunities would be one, only seemingly insignificant, point of departure for counteracting alienated and alienating machinic lives. To begin, it would require a much larger quantity of publicly available resources of the kinds implemented, for software, by Linux repositories or platforms such as Gitlab and Stackoverflow. Error handling could here return to everyday human readability, rather than requiring a specialist or, worse, specialist software to decipher what the original software aims to tell its user. A second step would then require publicly maintained error libraries alongside forums dealing with fixing them. Linux's Wiki system and Stackoverflow's forums are existing examples for this. For hardware, however, corporate control often thwarts efforts of this kind. ${ }^{3}$

Alongside such resources, secondly, a shift in individual attitudes would be required. To be sure, not everyone can be expected to build their own version of Arch Linux. Yet advocating people take time to understand their machinic companion may not be a fool's errand in the age of wellness apps and mindfulness retreats. One would do well to return to the attitudes of early computing as summed up in a 1982 handbook for the ZX81 minicomputer: “And if you ever find yourself thinking, 'What would happen if...?' then for goodness sake try it! You won't break the ZX81 and you'll probably learn something” (Norman 1982: 3). As a 1962 handbook on computer programming suggested: once the computing machine is understood, the programmer "will have the basic tools of programming at his [sic] fingertips but only practical experience as a working programmer can develop the knowledge and skill required to be considered an expert" (Saxon and Plette 1962: vii). It is not an accident that encouragement of this kind is much harder to find today.

What hinders this shift, and thus the third element to be addressed, is the commercially entrenched attitude to everyday machines, where they are seen either as mere tools towards one's job or entertainment, or they are violent status symbols, manifestations of private or public conspicuous consumption, or they are tools of managerial control. In the first and third cases, an error is a nuisance interrupting accumulation; in the second, it is an unacceptable weakness. Developing an appreciation for machinic actancy can counter this and work towards a less alienated existence. At the very least, such appreciation will entail a recognition of machinic creativity in its various forms, from glitches recognized as a genuine manifestation of a machine's own materiality, to rethinking mechanisms of attribution by which the work of Generative Networks is credited to humans.

\section{| 6. Conclusion: Alienated Artificial Intelligence?}

Thus even within alienated society, it is both necessary and possible at least to attempt to understand machines as individual entities in themselves. Observing the capricious individuality of machines in their everyday existence, one might develop an attitude resembling that of "a sociologist or psychologist of machines, living in the midst of this society of technical beings as its responsible and inventive consciousness” (Simondon 2017: 19).

As Artificial Intelligence moves further and further from the conceptual realm to actual implementation examples such as the above Generative Networks demonstrate at least a good amount of potential - the question facing any such sociology or psychology of machines is how they will come to be alienated, and how this alienation can be mitigated. It will be necessary to develop at least a changed everyday attitude, absent a more thorough social liberation from alienated society. As Artificial Intelligence develops towards embodiment, there is ample need to allow machines to constitute themselves as everyday companions, lessening their alienation along with that of humans and the environment. Widespread fears of Artificial Intelligence show that changes towards more seriously engaging machines and particularly smart - or indeed intelligent - machines, on their own terms are much needed. Some caution is, of course, advised - after all, the 'A.I.' revolution was said to be ten-to-fifteen years away in 1960 just as it was in 2010 - yet being mindful of one's machinic cohabitants would allow humans to come to terms with more or less sentient robotics a lot more easily.

Assuming that the current trends towards blurring the ontological boundaries between human and artificial intelligence continue, working towards reducing the alienation of machines may well become a fundamental social 
necessity. Even refraining from discussions about personhood for artificially intelligent beings, it will lower the bar for such conversations to take place. If intelligent robots are not developed, too, and machines remain merely 'smart', adjusting one's approach to them is crucial for reducing their alienation and with it that of humans and the environment. Thinking of machines as individual entities with life cycles would go a long way towards realizing what happens before and after one adopts and discards one's machinic companions. Exposing the alienated existence of computing machines can be instrumental in exposing that of alienated humans amid environmental destruction. Finally, machines also have characteristics of their own, and ignoring those contributes to their, and our, alienation.

\section{Endnotes}

1. Written with the help of an ASUS T100 alienated from its Intel Z3775's technicity by Windows 10 and LibreOffice Writer, to whom I owe many thanks. I would also like to thank two anonymous reviewers for their extensive and helpful comments.

2. To be sure, the 2018 case surrounding e-waste recycling businessman Eric Lundgren - who is now in prison - is, it seems, largely based on questions of copyright. Particularly, it appears that the prosecution's argument rested on claims Lundgren had sold repair kits containing counterfeit software. Since this software is feely available, however - which the prosecution has conceded - it is difficult to see the judgment as anything other than an attempt to chill efforts of machinic restoration (Swearingen 2018).
3. Sweeping statements from either side notwithstanding, the issue here is more complicated than pitting proprietary hardware against open source hardware. To take just one obvious example: in 2010, an article describing Apple's relation to open source hard- and software was entitled "Why Apple Hates Open Source" (Gralla 2010), while in 2016, another discussing the same issue could reference "the false debate between open and closed in tech" (Mossberg 2016). Nevertheless, open source hardware is considerably harder to come by than open source software, with major players like Arduino being an exception that rather proves the rule.

\section{References}

Agger, Ben. 1992. The Discourse of Domination. Evanston: Northwestern University Press.

Anders, Gunther. 1981. Die Antiquiertheit des Menschen. Munich: Beck Publishing.

Berghel, Hal. 2017. "Oh, What a Tangled Web: Russian Hacking, Fake News, and the 2016 US Presidential Election," Computer, 50(9): 87-91.

Booth, Robert.2019. "UK businesses using artificial intelligence to monitor staff activity,” The Guardian, 7 April 2019. Retrieved at https://www.theguardian.com/technology/2019/apr/07/ uk-businesses-using-artifical-intelligence-to-monitor-staff-activity.

Braverman, Harry. 1974. Labor and Monopoly Capital. NY and London: Monthly Review Press.

Cheney, Ann. 2010. “'Most Girls Want to be Skinny': Body (Dis) Satisfaction Among Ethnically Diverse Women," Qualitative Health Research, 21(10): 1347-1359.
Chung, Hyunji, Michaela Iorga, Jeffrey Voas and Sangjin Lee. 2017. “Alexa, Can I Trust You?” Computer, 50(9): 100-104.

Coyle, Diane. 2018. "In the service sector, time is a better measure of productivity," Financial Times, 30 January 2018. https:// www.ft.com/content/489f1ba2-04ee-11e8-9650-9c0ad2d7c5 b5.

Denning, Peter, Jack Dennis and Joseph Qualitz. 1978. Machines, Languages, and Computation. Englewood Cliffs: Prentice-Hall.

Elgammal, Ahmed, Bingchen Liu, Mohamed Elhoseiny and Marian Mazzone. 2017. "CAN: Creative Adversarial Networks, Generating 'Art' by Learning About Styles and Deviating from Style Norms," International Conference on Computational Creativity, Atlanta, 20-22 June 2017. https:// arxiv.org/pdf/1706.07068.pdf.

Ellul, Jacques. 1964. The Technological Society. New York: Vintage Books. 
Fisher, Eran. 2012. "How Less Alienation Creates More Exploitation? Audience Labour on Social Networking Sites," tripleC - Communication, Capitalism \& Critique, 10(2), 171-183.

Florida, Richard. 2014. The Rise of the Creative Class - Revisited: Revised and Expanded. New York: Basic Books.

Giedion, Siegfried. 1948. Mechanization Takes Command. A Contribution to Anonymous History. New York: W. W. Norton Co.

Gonzalez, Robbie. 2018. "Hey Alexa, What Are You Doing To my Kid's Brain?” Wired, 5 November 2018. https://www.wired. com/story/hey-alexa-what-are-you-doing-to-my-kids-brain/.

Gralla, Preston. 2010. "Why Apple Hates Open Source," PCWorld, 11 March 2010. https://www.pcworld.com/ article/191216/why_apple_hates_open_source.html.

Harrison, Todd. 2016. Defense Modernization Plans through the 2020s: Addressing the Bow Wave. Lanham etc: Rowman \& Littlefield.

Hegarty, Paul. 2007. Noise/Music. A History. London: Continuum.

Heskett, James. 1987. "Lessons in the Service Sector," Harvard Business Review, March 1987. https://hbr.org/1987/03/ lessons-in-the-service-sector.

Hirsch, Afua. 2013. “'This is not a good place to live': Inside Ghana's dump for electronic waste," The Guardian, 14 Dec 2013. https://www.theguardian.com/world/2013/dec/14/ ghana-dump-electronic-waste-not-good-place-live.

Ihde, Don. 2015. "Preface: Positioning Postphenomenology." In Robert Rosenberger and Peter-Paul Verbeek (eds.): Postphenomenological Investigations: Essays on HumanTechnology Relations (Lanham, MD: Lexington Books), i-xxx.

Jaeggi, Rahel. 2014. Alienation. New York: Columbia University Press.

Jay, Martin. 1973. The Dialectical Imagination. London: Heinemann Educational.

Jones, Owen. 2018. "Talk to Deliveroo couriers. See a dystopia that could be your future," The Guardian, 24 May 2018. https://www.theguardian.com/commentisfree/2018/may/24/ deliveroo-couriers-dystopia-union.

Latour, Bruno. 1993. We Have Never Been Modern. Cambridge, MA: Harvard University Press.

Mamidipaka, Mahesh, Dan Hirschberg and Nikil Dutt. 2004. "Efficient Power Reduction Techniques for Time Multiplexed Address Busses," Proceedings of the 15th international symposium on system synthesis, 207-212.

Marx, Karl. 1844/1975. "Economic and Philosophic Manuscripts of 1844.” In Robert Tucker (ed.): The Marx-Engels Reader (New York: W.W.Norton Co.), 66-125.
Marx, Karl and Friedrich Engels. 1845/1975. "The German Ideology: Part I.” In Robert Tucker (ed.): The Marx-Engels Reader (New York: W.W.Norton Co.), 146-200.

McCue, TJ. 2018. "57 Million U.S. Workers Are Part Of The Gig Economy.” Forbes online, 31 August 2018. https://www. forbes.com/sites/tjmccue/2018/08/31/57-million-u-s-workers-are-part-of-the-gig-economy/\#3fe8d7b07118.

Meynaud, Jean. 1968. Technocracy. London: Faber \& Faber.

Mossberg, Walt. 2016. "Mossberg: the false debate between open and closed in tech," The Verge, 16 March 2016. https://www. theverge.com/2016/3/16/11242266/walt-mossberg-open-vsclosed-software-apple-os-x-google-android.

Noble, David. 1993. Progress Without People. In Defense of Luddism. Chicago: Charles H. Kerr.

Norman, Robin. 1982. ZX81 Basic Book. Indianapolis: Howard W. Sams \& Co.

Parkin, Simon. 2019. "The rise of the deepfake and the threat to democracy," The Guardian, 22 June 2019. https://www. theguardian.com/technology/ng-interactive/2019/jun/22/ the-rise-of-the-deepfake-and-the-threat-to-democracy.

Phillips, Gary, Sanjiva Nath and Terry Silveria. 1984. The Commodore 64 User's Encyclopedia. Los Angeles: The Book Company.

Pierce, J.R. 1961. Symbols, Signals and Noise. New York: Harper \& Row.

Rhodes, Richard (ed). 1999. Visions of Technology. New York: Simon and Schuster.

Roszak, Theodore. 1994. The Cult of Information. Berkeley \&c: University of California Press.

Saxon, James and William Plette. 1962. Programming the IBM 1401: A Self-Instructional Programmed Manual. Englewood Cliffs: Prentice-Hall.

Schmitt, Thomas and Christian Schulz. 2016. "Sustainable resource governance in global production networks Challenges for human geography," Erdkunde, Vol. 70 No. 4, 297-312.

Scholz, Trebor. 2015. "Think Outside the Boss. Cooperative alternatives to the sharing economy." Public Seminar Blog, 5 April 2015. http://www.publicseminar.org/2015/04/ think-outside-the-boss/

Simondon, Gilbert. 2017. On the Mode of Existence of Technical Objects. Minneapolis: University of Minnesota Press.

Smith, Brian. 1998. On the Origin of Objects. Cambridge and London: MIT Press.

Stecher, Benjamin. 2017. "Artificial Intelligence Is Already a Better Artist Than You Are," Futurism, 2 April 2017. https:// futurism.com/artificial-intelligence-already-better-artist-you. 
Sturt, David and Todd Nordstrom. 2018. "Bored At Work? Science Says That's A Good Thing,” Forbes online, 24 May 2018. https://www.forbes.com/sites/davidsturt/2018/05/24/boredat-work-science-says-thats-a-good-thing/\#1269257a4c91.

Swearingen, Jake. 2018. "Why Is This Man Going to Prison for Copying Free Repair Software?” New York Magazine Intelligencer, 8 May 2018. http://nymag.com/intelligencer/2018/05/why-is-eric-lundgren-in-prison-for-copying-dellrestore-cds.html.
Wang, Dan. 2016. "How smartphones made Shenzhen China’s innovation capital," Vox, 4 November 2016. https:// www.vox.com/new-money/2016/11/4/13498504/ shenzhen-smartphone-innovation-capital.

Zerzan, John. 2012. Future Primitive Revisited. Port Townsend: Feral House. 
